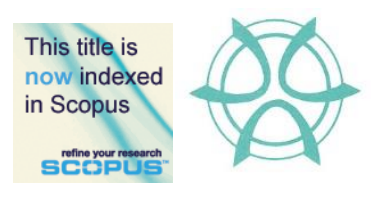

PLANNING MALAYSIA:

Journal of the Malaysian Institute of Planners

VOLUME 15 ISSUE 1 (2017), Page 117 - 128

\title{
APPRECIATION OF VERTICAL GREENERY IN A CITY AS PUBLIC ART
}

\author{
Mazlina Mansor ${ }^{1}$, Khalilah Zakariya ${ }^{2}$, Nor Zalina Harun ${ }^{3}$, \& Nur Izzah Abu \\ Bakar $^{4}$ \\ ${ }^{1,2,3,4}$ Kulliyyah of Architecture and Environmental Design \\ INTERNATIONAL ISLAMIC UNIVERSITY MALAYSIA
}

\begin{abstract}
Vertical greenery $(\mathrm{VG})$ is greenery where plants can be grown on, up, or against internal or external walls of buildings or as freestanding structures. Whereas, public art (PA) is a structure or form that contains an artistic expression. It is placed in public spaces. VG has gained tremendous popularity in recent years, and this offers an opportunity to integrate it as a part of public art in cities. A place with a combination of art and aesthetics with environmental principles would become a new urban art that will help extend VG's survivability and human security in the future. Most research in VG focuses on an environmental and technical aspect that consider its benefits, technical issues, feasibility, acoustic impact, sustainability, system and maintenance. On the other hand, creative methods to approach VG are seldom researched upon especially in Malaysia. Hence, this study explores this possibility from the public's perspectives. The objectives were to identify public's familiarity and values of VG as PA, and VG attributes to be as a PA. An online survey was used to obtain public's perspectives on the integration of VG as PA. The target respondents were the public, whereby the link to the survey was sent out to 400 potential respondents. The survey obtained 117 responses, and they were gathered automatically in an Excel spreadsheet. The data were converted into the themes to generate results. Findings yield positive outcomes in terms of the public's familiarity of the terminologies (i.e. VG and PA), people's awareness of VG in an urban environment, and the possibilities and potentials of VG to become a PA in Malaysian cities. It means that VG has extended beyond the environmental benefits to also become an art form for people in a city.
\end{abstract}

Keyword: Vertical greenery, public art, integration, sustainability

Date Received: $30^{\text {th }}$ April 2016

Date of Acceptance: $30^{\text {th }}$ October 2016 
Mazlina Mansor, Khalilah Zakariya, Nor Zalina Harun, \& Nur Izzah Abu Bakar

Appreciation of Vertical Greenery in A City as Public Art

\section{INTRODUCTION}

This research focuses on the potential of vertical greenery (VG) to be appreciated as public art (PA) in a city. VG is greenery where plants can be grown on, up, or against internal or external walls of buildings or acts as freestanding structures. PA is a structure or form that contains an artistic expression. It is placed in a freely accessible public space for people to view. In the 80's, there was a growing interest in environmental issues. The scenario has triggered a vision of bringing nature into cities, environmentally and aesthetically. VG is suitable in urban places, as there is insufficient urban green spaces. VG is increasingly being implemented in the city's public spaces and buildings to improve the urban life quality and ecosystems, as well as to upgrade urban realm. VG can modify temperature, improves air quality and increases biodiversity. Contact with greenery in city is also said to improve people's physiology and mental health. Hence, VG has gained tremendous popularity in recent years to be erected in public spaces. This popularity offers a great opportunity for it to be appreciated as a part of public art in city spaces. It is implied that a place with a combination of art, aesthetics and environmental principles would become a new urban art that helps to extend the survivability of VG. The interest will not be just a passing trend for one time only (Séguin, 2012).

Furthermore, most researches on VG were centred on the environmental and technical aspects, such as on the benefits, technical issues, feasibility, acoustic, sustainability, system and maintenance of VG (Peck et al., 1999; Watts, 2009). However, the creative methods to approach VG were seldom researched upon especially in Malaysia. Hence, this paper explores the views and acceptance of city residents on the creative methods to appreciate VG in public spaces. Recent increase in the popularity of VG has created the possibility to incorporate VG as 'green public art' into city spaces. The aim is to identify the possible ways VG can be appreciated as public art (PA).

\section{LITERATURE REVIEW}

There is a growing trend of using the VG system to green urban public spaces. There is also a definite need to improve the selection and appearance of PA in Malaysia (Shunmugam, 2006; Mohd Fabian et al., 2012). PA in Malaysia is claimed only typically to decorate and fill empty spaces of a public area. It lacks art quality, unable to command people's attention or evoke deeper feelings to the public. Hence, VG is seen as a new way to creatively attract the public to appreciate PA.

The utilization of VG for its beauty and functions can be traced back to as early as the $500 \mathrm{BC}$. For instance, the Hanging Gardens of Babylon applied terrace structure over arch stone beams, and were waterproofed with thick layers of reeds and tar. More recently, the garden city movement jump-started the concern and care for the environment in urban spaces in the 1920's. During the 
PLANNING MALAYSIA

Journal of the Malaysia Institute of Planners (2017)

garden city movement, Stanley Hart White, a professor in Landscape Architecture field had patented a vertical greenery system for environmental benefits, known as Vegetation-Bearing Architectonic Structure and System (Hindle, 2012). However, due to the public's concern about the strength of the structure, the concept was not popular at the time.

To understand VG's association with PA, a history of PA also needs to be considered. The term 'public art' was first coined in 1959 when the first Percent-for-Public Art ordinance in the United States was adopted by the city of Philadelphia, Pennsylvania (Cartiere \& Willis, 2008). However, PA was only used for its aesthetic value during the time. In 1967, PA started to be used for environmental, aesthetic and social values. Concurrently, from the 1960's to 1980 's, PA started to be adopted in Malaysia. Nonetheless, most of the artworks at this time were influenced by the post-formalist approach. However, in the late 70 's, as Islamic consciousness increased, more artists began to align themselves with abstract-expressionist style, as well as Islamic centred art (Sarena, 2011). PA during this time was designed for its social, environmental and aesthetic benefits. The awareness of Land Art has also started to emerge parallel to this event as artists becoming more concern about environmental issues (Irons, 2012). This led to more interest in environmental issues, resulting in the vision of bringing nature into cities was conceived in the 80 's. At the same time in Malaysia the artworks were began to be influenced by environmental awareness, social democracy and human rights (Sarena, 2011) and they began to use recycled materials in their artworks and diverse art techniques.

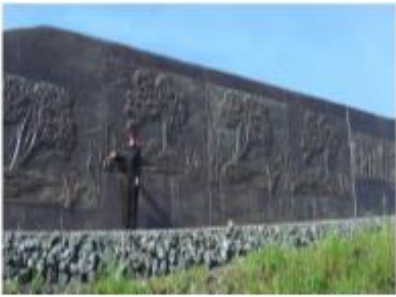

Integrated art

Art that is physically attached to

or exists as an aspect of the infrastructure. It may integrate with landscape feature (walls railing/fence or pavement)

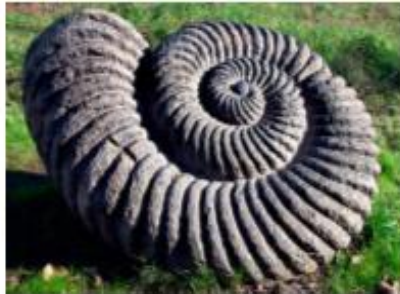

Environmental art. Art that portrays interr elationship of hum an and nature. May use natur al materials to convey its m eaning.

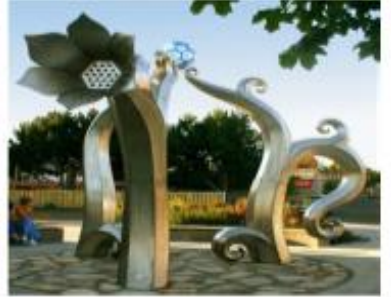

Stand alone art Sculptur al artwork that is placed within the right of way where there is adequate space and viewing opportunity.

Figure 1 Three Types of Public Art (PA)

In 1988, Patrick Blanc's re-introduced the concept of modern VG to the world that was already initiated by Professor White in 1938. One of the most prominent examples of VG in Blanc's works was a palette of foliage that creates a subtle mixture of effects, forms and shades over the surface of walls. It has put 
Mazlina Mansor, Khalilah Zakariya, Nor Zalina Harun, \& Nur Izzah Abu Bakar

Appreciation of Vertical Greenery in A City as Public Art

the VG system into the limelight whereby it was appreciated for its environmental and aesthetical utilisation.

Over the years, both VG and PA have gone through many stages of development. What can be determined from this is that the integration of both produces many benefits to city spaces. Their application and usage could be explored in many other creative ways. The sustainability of urban landscape can be generated when the site, art and people are integrated. Buildings around the world have embraced VG for its environmental, aesthetic and economic values. The application of green concepts for urban design cityscapes is made obligatory in some parts of the world. These have popularised the installation of vegetation on external street walls. For instance, a piece of garden wall art can enhance the experiential quality of the adjacent space by providing an aesthetically pleasing, calming and the environment that is closer to nature (Chin, 2010). VG as PA is an urban greening project, which creates an environment for people to be comfortable shopping, working or living, and their community's character is expressed (Watts, 2009). Hence, successful urban greening projects will be worthwhile and rewarding in the long term for the community. Currently, VG has often showcased beautiful patterns and becoming a new urban art in a city (Séguin, 2012).
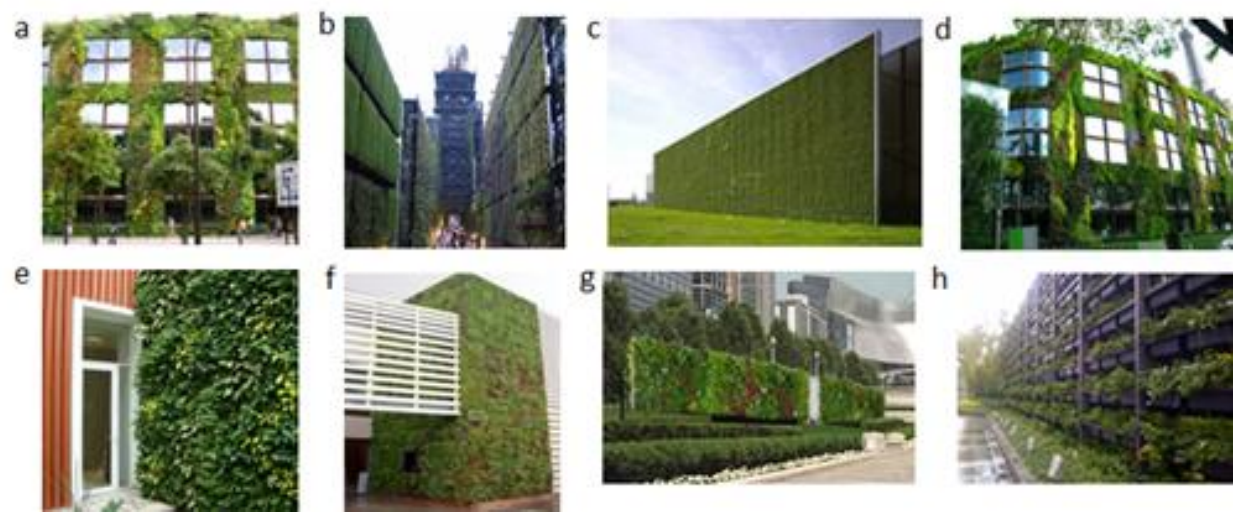

Figure 2 (a) vertical garden (VGr); (b) bio façade wall (BW); (c) green wall (GW); (d) green façade (GF); (e) vertical greenery system (VGS); (f) green scaffolding (SG); (g) green space wall (GSW); (h) living wall (LW)

Several types of VG have the potential to become PA in urban public space (Figure 2). Vertical garden (VGr) is all forms of plant surface of the wall. It allows the growing of plants, up, or on the façade of buildings (Baskaran, 2003; Green Public Art, 2010). Bio facade wall (BW) is vegetation that is guided to climb through the structure like wires or cables. Green wall $(\mathrm{GW})$ is all forms of vegetation surface, while green facade (GF) is climbing plants or cascading 
PLANNING MALAYSIA

Journal of the Malaysia Institute of Planners (2017)

groundcovers trained to cover designed supporting structures (Badrulzaman, 2011). Vertical greenery system (VGS) is a way in which plants can be grown on, up, or against a façade of a building or feature walls (Wong et al., 2010). Green scaffolding (GS) applies mainly to eco-retrofitting, essentially wraps a lightweight structure around the exterior of existing buildings. Green space wall (GSW) is an eco-sphere that doubles as an exterior wall or mixed interior/exterior spaces in new development (Birkeland, 2008). Living wall (LW) consists of prevegetated panels, vertical modules or planted blankets that are fixed vertically to a structural wall or structure (Chin, 2010).

\section{METHODOLOGY}

An online survey was used to identify public's familiarity and responses on the integration of VG as PA. Electronic survey is becoming increasingly common because it provides strong advantages such as speedy distribution and response cycles, the ability to conduct large-scale distribution of a questionnaire to prospective respondents, and cost less compared to postal mail survey (Yun \& Trumbo, 2000; Lazar \& Preece, 1999). The questionnaire consisted of three sections. The first section recorded the respondent's background. The second section dealt with familiarity with the terms VG and PA. The third section explored public's views on the integration between VG and PA. The survey questions consisted of mainly closed-ended question, supported by pictorial questions and open-ended questions.

A link to the survey was sent online to potential respondents, where the respondents were automatically directed to the Google Form survey. The survey was pre-tested and fine-tuned before being distributed to the respondents. The target respondents were the Malaysian public, and the link to the survey was sent out to almost 400 potential respondents. The survey was opened for two months to allow potential respondents ample time to answer. All in all, the survey managed to gather 117 responses.

Several steps were used to analyse the online responses. The responses were automatically recorded in Excel spreadsheet and later sorted into respective themes to generate frequency distributions. The analysis process began with familiarizing the data. This phase involved reading and re-reading the responses to become familiar with its content. Important dimensions from the responses were selected using categorical analysis. Descriptive analyses were used to analyse the closed-ended questions using percentage from frequency distributions derived from the Excel spreadsheet. For the open-ended questions, category headings were used to theme the results about the objectives of the study. In this case, categorising the responses that the respondents replied and suggested based on the parameters. 
Mazlina Mansor, Khalilah Zakariya, Nor Zalina Harun, \& Nur Izzah Abu Bakar

Appreciation of Vertical Greenery in A City as Public Art

\section{FINDINGS}

\section{Respondents' Profile}

The minimum age of the respondents was limited to 18 years or older to ensure that the respondents were adults. $64 \%$ of the respondents are within the age of $18-30$ years old. $24 \%$ are within the age of 31-40 years old, $8 \%$ within $41-50$ years old, and 4\% within 51-60 years old. More than half of the respondents were female $(62 \%)$. Almost half of the respondents are professionals (43\%). $21 \%$ of them are academicians, $19 \%$ students and the rest $(17 \%)$ consisted of various groups of professions. Regarding the place of residence, $50 \%$ of the respondents reside in Selangor, $21 \%$ in Kuala Lumpur and the others $(28 \%)$ live in other states in Malaysia. $57 \%$ of the respondents have degree qualification and $32 \%$ have postgraduate qualification. $8 \%$ of the respondents are diploma holder and $3 \%$ only have secondary school education.

\section{Familiarity with Vertical Greenery and Public Art}

Concerning familiarity, less than half of the respondents (48\%) are familiar with the term vertical greenery (VG). It is because VG is a new term among Malaysians, and it is associated with terms that are closer to it such as vertical wall and green wall. The public might have encountered it before, but unsure of the terms used to describe it.

Eight types of VG, as in described in Figure 2, were shown to the respondents using images in pictorial questions. As shown in Table 1, most of the respondents are familiar with the VGS (71\%), followed by GF (69\%), LW (67\%) and BW (56\%). Less than half of the respondents are familiar with the GW (48\%), VGr (45\%), GS (39\%) and the GSW (34\%). 56\% of the respondents have seen the VGS in the public spaces. The results suggest that even though the respondents are not very familiar with the term VG, they do recognised the types of VG images that were shown in the survey. Some have also seen it personally. Overall, the results suggest that even though VG is a new term of landscape approach in Malaysia, the public is quite familiar with it.

Table 1 Familiarity with Types of VG

\begin{tabular}{|c|c|c|c|c|c|c|c|c|c|}
\hline \multicolumn{2}{|l|}{ Variables } & VGr & BW & GW & $\mathrm{GF}$ & VGS & GS & GSW & LW \\
\hline \multicolumn{2}{|c|}{ Familiarity on types of VG $(\%)$} & 45 & 56 & 48 & 69 & 71 & 39 & 34 & 67 \\
\hline \multicolumn{2}{|c|}{$\begin{array}{l}\text { The types of VG that respondents } \\
\text { have seen in a public area }(\%)\end{array}$} & 26 & 40 & 22 & 49 & 56 & 26 & 21 & 48 \\
\hline \multirow{3}{*}{$\begin{array}{l}\text { Location of } \\
\text { VG being } \\
\text { displayed }\end{array}$} & Selangor & 3 & 13 & 11 & 16 & 8 & 10 & 3 & 12 \\
\hline & Kuala Lumpur & 9 & 3 & 6 & 9 & 18 & 7 & 12 & 24 \\
\hline & Others & 7 & 4 & 3 & 4 & 4 & 4 & 6 & 15 \\
\hline
\end{tabular}


In terms of familiarity with the PA term, majority (78\%) of the respondents is familiar with the term. Three types of PA, namely the integrated art (integrated walls-IW, integrated fence-IF), environmental art (EA) and standalone art (SAA) were shown to the respondents to identify their familiarity and preference of PA in the urban public space. The finding is necessary to understand the public's knowledge about PA. Results on the familiarity of different types of PA are shown in Table 2.

Table 2 Familiarity with Types of PA and the Preferred PA

\begin{tabular}{|c|c|c|c|c|}
\hline \multirow{2}{*}{ Variables } & \multicolumn{2}{|c|}{ IA } & \multirow{2}{*}{ EA } & \multirow{2}{*}{ SAA } \\
\hline & IW & IF & & \\
\hline Familiarity with types of PA $(\%)$ & 93 & 79 & 73 & 92 \\
\hline Preferred PA $(\%)$ & \multicolumn{2}{|c|}{20} & 46 & 34 \\
\hline
\end{tabular}

Note. Highlighted figures are the highest frequency (\%)

The respondents are most familiar with IW (93\%) followed by standalone art SAA (92\%), IF (79\%) and EA (73\%). The result shows that the Malaysian public is more familiar with the term PA as compared to the term VG. Regarding preference in types of PA, the result shows that the respondents preferred EA out of all types of PA (46\%). It is followed by SAA (34\%) and IA (20\%). The result suggests that even though the respondents are more familiar with IW (integrated wall), they prefer EA (environmental art) and would like to see more EA being implemented in the urban spaces. Also, these findings reveal that the public is aware of the importance of having more environmental-friendly PA in urban public spaces.

\section{Integration of Vertical Greenery as Public Art}

To assess respondents' familiarity and views whether VG can be appreciated as PA, they were asked to identify four types of VG that can act also as a PA. These are VG as IW, VG as IF, VG as EA and VG as SAA. To assist the respondents, pictorial questions with the image of the abovementioned VG were provided in the survey. Results are shown in Table 3.

The results show that the public in Malaysia is not yet very familiar with the integration between VG and PA. About half of the respondents (43\%) pointed out that they are familiar with VG as EA. Nonetheless, $85 \%$ of the respondents stated that they have seen VG as SAA in urban public spaces in Malaysia. The results show that the public is familiar with the VG as PA in Malaysia even though they seldom encounter the artwork personally in urban public space, but have seen the artwork being displayed in Malaysia in the media. It shows that although VG was still not widely implemented as PA as compared to other countries, the implementation has already started in Malaysia. Thus, it would not be a hindrance for it to be widely implemented in Malaysia. 
Mazlina Mansor, Khalilah Zakariya, Nor Zalina Harun, \& Nur Izzah Abu Bakar Appreciation of Vertical Greenery in A City as Public Art

Table 3 Familiarity of VG as PA

\begin{tabular}{llcccc}
\hline Variables & Detail & $\begin{array}{c}\text { VG as } \\
\text { IW }\end{array}$ & $\begin{array}{c}\text { VG as } \\
\text { IF }\end{array}$ & $\begin{array}{c}\text { VG as } \\
\text { EA }\end{array}$ & $\begin{array}{c}\text { VG as } \\
\text { SAA }\end{array}$ \\
\hline $\begin{array}{l}\text { Familiarity with VG as PA } \\
(\%)\end{array}$ & $\begin{array}{l}\text { Yes } \\
\text { No }\end{array}$ & 42 & 23 & 43 & 23 \\
\hline $\begin{array}{l}\text { Familiarity of VG as PA } \\
\text { being displayed in urban } \\
\text { public space in Malaysia } \\
(\%)\end{array}$ & No & 80 & 84 & 74 & 85 \\
\hline $\begin{array}{l}\text { Location of VG as PA (\%) } \\
\text { Selangor } \\
\text { Kuala } \\
\text { Lumpur } \\
\text { Other } \\
\text { states }\end{array}$ & 16 & 15 & 23 & 10 \\
\hline
\end{tabular}

Note. Highlighted figures are the highest frequency (\%)

On the idea to integrate VG as PA, $92 \%$ of the respondents agreed with the idea to integrate VG as PA. It shows that the public is very interested in the idea to implement VG as PA. An analysis of the survey data found seven dimensions or reasons for their agreement for the appreciation of VG as PA (Table 4).

Table 4 Integration of VG as PA

\begin{tabular}{lc}
\hline Reasons to integrate VG as PA & Frequency (no) \\
\hline 1. Aesthetic: aesthetic value, attractive & 9 \\
\hline 2. Environment & 8 \\
Mitigate greenhouse effect; pollution & 12 \\
Nature; balance development; scenery & 11 \\
Environmentally friendly & 2 \\
Native plant species & 1 \\
Health benefits & 2 \\
Minimum land usage & 11 \\
\hline 3. Awareness & 2 \\
Promote message to public & 9 \\
Greener Malaysia; appreciate green art & 7 \\
\hline 4. Economic & 5 \\
Attract tourism; economic benefit & 2 \\
Enhance space value & 9 \\
\hline 5. Design & 3 \\
Possible trend & 6 \\
Unique; creative; Providing varieties & 1 \\
\hline 6. Development of VG - improve & \\
\hline
\end{tabular}


PLANNING MALAYSIA

Journal of the Malaysia Institute of Planners (2017)

\begin{tabular}{ll}
\hline 7. Development of PA & 6 \\
Promote green art; awareness on PA & 3 \\
Quality PA; artistic; diversity of PA & 3 \\
Support social needs & 1 \\
\hline
\end{tabular}

The most cited reason by respondents is that VG is good to be appreciated as PA for the care of the environment (36 times). The respondents suggest that it can mitigate the greenhouse effect, bring nature in cities, environmentally friendly, improve the scenery, produce environmental benefits, utilise many plant species in Malaysia, mitigate pollution problems, balance between development and nature, health benefits, and minimum land usage. Among the respondents' insights on this is "...The development always concerns on the buildings and the facilities. Everything is made up of concrete and metal. It is a good idea to implement the greenery in the area for the aesthetic value of the area, landmarks, and most importantly the environment, such as cooling down the area, cleans the air, etc.. '. The response shows that the idea to integrate VG as PA is well accepted by the public and the idea would have a bright future to be realised.

\section{The Attributes of Vertical Greenery as Public Art}

Questions on the attributes of VG as PA preferred for city spaces in Malaysia were also included in the survey. Table 5 shows the respondents' answers, where $59 \%-78 \%$ of the respondents preferred all types of VG to be moderate in size. In terms of colour, $56 \%-67 \%$ preferred it to be a combination of warm and cool colour. 56\% - 67\% agreed for the VG to be located outdoor rather than indoor. For the design attribute, $84 \%-92 \%$ favoured the VG to be a combination of natural and formal design. Finally, $45 \%-56 \%$ prefer the material to be a combination of natural, recycled and new materials. These responses would help designers to have ideas on the attributes that should be taken into consideration when designing VG as PA.

Table 5 Preferred Attributes of the Implementation of VG as PA

\begin{tabular}{llccccc}
\hline \multirow{2}{*}{ Attributes } & \multirow{2}{*}{ Dimension } & \multicolumn{4}{c}{ Vertical Greenery as Public Art (\%) } & \multirow{2}{*}{ Remarks } \\
& & VG as IW & VG as IF & VG as EA & VG as SAA & \\
\hline \multirow{3}{*}{ 1. Size } & Small & 0 & 9 & 1 & 10 & \multirow{2}{*}{ Size: Moderate } \\
& Moderate & 62 & 78 & 59 & 61 & Range: $50 \%-80 \%$ \\
& Large & 38 & 14 & 37 & 26 & \\
\hline \multirow{3}{*}{2. Colour } & Warm & 4 & 5 & 11 & 10 & \\
& Cool & 29 & 32 & 28 & 24 & Colour: Combination \\
& Combination & 67 & 61 & 56 & 61 & Range: $50 \%-70 \%$ \\
\hline \multirow{2}{*}{ 3. Location } & Indoor & 5 & 7 & 3 & 9 & Location: Outdoor \\
& Outdoor & 92 & 91 & 91 & 84 & Range: $80 \%-92 \%$ \\
\hline
\end{tabular}


Mazlina Mansor, Khalilah Zakariya, Nor Zalina Harun, \& Nur Izzah Abu Bakar Appreciation of Vertical Greenery in A City as Public Art

\begin{tabular}{llccccl}
\hline \multirow{3}{*}{ 4. Design } & Natural & 27 & 27 & 29 & 22 & \\
& Formal & 5 & 10 & 8 & 10 & \\
& Combination & 66 & 57 & 57 & 62 & $\begin{array}{l}\text { Design: Combination } \\
\text { Range: } 50 \%-70 \%\end{array}$ \\
\hline \multirow{5}{*}{ 5. Materials } & Natural & 23 & 24 & 25 & 23 & \\
& Recycle & 18 & 17 & 15 & 15 & \\
& New & 3 & 5 & 9 & 8 & Material: \\
& Combination & 56 & 45 & 45 & 50 & Combination \\
& & & & & & Range: $40 \%-60 \%$ \\
\hline
\end{tabular}

Note. Highlighted figures are the highest percentage (\%)

Most importantly, the open-ended question on the preference of attributes also produced many valuable suggestions. 27 responses were obtained from the respondents, which can be categorised into 14 dimensions as shown in Table 6 . The highest frequency of the attribute is in the choice of plants. The public suggests the consideration of Malaysian native plants, the plants' habitat, aromatic plants and medicinal plants. The result implies that the public can accept the idea to integrate VG as PA and is very keen on it.

Table 6 Additional Attributes Derived from Respondents' Responses

\begin{tabular}{lc}
\hline Attributes & $\begin{array}{c}\text { Frequency } \\
\text { (nos.) }\end{array}$ \\
\hline 1. Maintenance - proper and easy maintenance; low & 5 \\
2. Function - shade; health benefits; good for LA Profession & 3 \\
3. Education - appreciate nature & 1 \\
4. Islamic Values & 1 \\
5. Location & 1 \\
6. Public acceptance & 1 \\
7. Types of plants - species; native plants; habitat; aromatic; medicinal & 6 \\
8. Supporting elements - recreational element & 1 \\
9. Irrigation system & 1 \\
10. Locality - cultural heritage elements; building facade's character & 1 \\
11. Awareness - message & 1 \\
12. Safety - no vandalism; safe & 2 \\
13. Design - retaining wall along the highways; green standing & 2 \\
14. Cost - management & 1 \\
\hline
\end{tabular}

\section{Recommendation for Vertical Greenery to Be Integrated As Public Art}

In terms of recommendations, 46 respondents provided ideas which were classified into seven categories (Table 7). Education and promotion (15 times) are the utmost importance to improve the integration. It is vital to educate the public to care for effort in the maintenance of the VG and to educate public to realize the idea. Awareness, strong promotion through mass media, promotion through expo and exhibits, 'bring back nature campaign', no vandalism 
PLANNING MALAYSIA

Journal of the Malaysia Institute of Planners (2017)

awareness, education using new technology and to educate the developers on the benefits of VG are among the suggestions.

Table 7 Recommendations to improve VG as PA in Malaysia

\begin{tabular}{lc}
\hline Potential Improvement & $\begin{array}{c}\text { Frequency } \\
\text { (nos.) }\end{array}$ \\
\hline 1. Government Initiatives & 11 \\
Government's Act; green living enforcement & 4 \\
Additional budget & 2 \\
Competition & 1 \\
Specific allocation of space & 1 \\
High score in GBI & 1 \\
Incentives/subsidy to developers/consultants; Cooperate with & 2 \\
private companies & \\
\hline 2. Function - benefits; multi-purpose & 3 \\
\hline 3. Education and Promotion & 15 \\
Educate public to maintain, realize the idea; awareness; no & 8 \\
vandalism awareness & 5 \\
Strong promotion through mass media; exhibition; campaign on & \\
nature & 1 \\
Education with new technology & 1 \\
Educate the developers & 2 \\
\hline 4. Location - strategic place; legible & 2 \\
\hline 5. Maintenance - low & 12 \\
\hline 6. Design & 6 \\
Implement at early stage of design; compulsory in contract; better & \\
design & 2 \\
Include in LA scope of work & 1 \\
Approach companies & 1 \\
Integrate VG with well-known Malaysian landmark & 1 \\
\hline Use climbing plants & 2 \\
\hline
\end{tabular}

\section{CONCLUSION}

VG can contribute to the quality of life as it serves numerous advantages towards a city. In ensuring the survivability of $\mathrm{VG}$ and sustainability of the urban environment, a creative way to implement green in urban public spaces must be explored. VG and PA complement each other in aesthetic, environment and economy. The integration of both will create not only public art that is high in aesthetic quality but also environmentally sound. The findings of this study suggest that the public is very keen to see more implementation of VG as PA in Malaysia. Hence, more emphasis should be given to developing a creative, innovative and quality environment that will later encourage further research on integrating VG as PA in the urban landscape. The public insights regarding this matter are very crucial for designers to come out with a sound recommendation 
Mazlina Mansor, Khalilah Zakariya, Nor Zalina Harun, \& Nur Izzah Abu Bakar

Appreciation of Vertical Greenery in A City as Public Art

of VG as PA. This exploratory study provides the stimulus for designers to rethink approaches to the functions, content and strategies for VG as PA.

\section{REFERENCES}

Badrulzaman J., Ismail S., \& Mohd Hisyam, R. (2011). Evaluating the impact of vertical greenery system on cooling effect on high rise buildings and surroundings: A review. SENVAR, Johor: Skudai. www.epublication. fab.utm.my/180/1/SENVAR1201

Baskaran, B. (2003). Evaluating rooftop and vertical gardens as an adaptation strategy for urban areas. Ottawa from http://lib.fo.am/_media/

Birkeland, J. (2008). Space frame walls: facilitating positive development. In G. Foliente, T. Luetzkendorf, P.Newton, \& P. Paevere (Eds.) The World Sustainable Building Conference (pp. 21-25). Victoria, Melbourne, Australia.

Cartiere C., \& Willis, S. (2008). The practice of public art (Eds.), New York: Taylor \& Francis.

Chin, M. Y. (2010, September). Wrapped in life-giving green. The Star Online. Retrieved from http://thestar.com.my/lifestyle/

Green Public Art (2010). Urban landscaping: green walls. Retrieved from http://greenpublicart.com/

Hindle, R. L. (2012). A vertical garden: origins of the Vegetation-Bearing Architectonic Structure and System (1938). An International Quarterly, 32(2), 99-110. doi: $10.1080 / 14601176.2011 .653535$

Irons, K. (2012). The purpose and value of public art. eHOW. Retrieved from http://www.ehow.com/

Lazar, J., \& Preece, J. (1999). Designing and implementing web-based surveys. Journal of Computer Information Systems, 39(4), 63-67.

Mohd Fabian, H., Osman, M. T., \& Mohd Nasir, B. (2012). Towards integrating public art in Malaysian urban landscape. Pertanika, Journal of Social Sciences \& Humanities, 20(2), 251-263.

Peck, S. W., \& Callaghan, C. (1999). Greenbacks from green roofs: forging a new industry in Canada. Status report, Canada Mortgage and Housing Corporation, March 1999.

Sarena, A. (2011). Thematic approaches in Malaysian art since the 1990s. Jati, 16, $97-$ 113.

Séguin, M. L. (2012). Green walls. Architecture Posts. Retrieved from http:// http://inhabitat.com/tag/green-wall/

Shunmugam, V. (2010, September). By the artists, for the people. The Star. Retrieved from http://thestar.com.my/lifestyle/

Watts, P. (2009). Ecoartspaceblog. Report from Seattle Public Art Conference; 2009. Retrieved from http://ecoartspace.blogspot.com/

Wong, N. H., Tan, A. Y. K., Chen, Y., Sekar, K., Tan P. Y., Chan, D., \& Chiang, K. (2010). Thermal evaluation of vertical greenery systems for building walls. Building and Environment, 45(3), 663-672. doi: 10.1016/ j.buildenv.2009.08.005

Yun, G. W., \& Trumbo, C. W. (2000). Comparative response to a survey executed by post, e-mail, \& web form. Journal of Computer-Mediated Communication, 6(1). doi: 10.1111/j.1083-6101.2000.tb00112.x 